\title{
ENERGI TERBAHARUKAN DAN PENINGKATAN EKONOMI: PENGOLAHAN KOTORAN SAPI BERLAPIS, DESA CIBODAS
}

\author{
Hendro Muliarto ${ }^{1}$ \\ 1Perencanaan Infrastruktur dan Transportasi, Program Studi Perencanaan Wilayah dan Kota, Institut \\ Teknologi Sumatera
}

\begin{abstract}
:
The debate over waste management practices has become a very important issue, human activities that have exceeded the burden of the biosphere's assimilative capacity are the cause. Waste is now recommended for recycling and energy recovery purposes. In principle waste requires management so as not to endanger the environment different from side products that can still be utilized. Side products such as cow dung or organic waste can be used as a source of energy, biogas. But biogas itself also issued a byproduct of biosulry. In Cibodas Village there is processing of layered cow dung with biogas scheme and biosulry fertilizer. Processing of layered cow dung provides many advantages for the people of Cibodas Village, in addition to new energy sources also generate new sources of income for the community.
\end{abstract}

Keyword: Side Products, Renewable Energy, Biogas, Bio Slurry, Cibodas Village

\section{Pendahuluan}

Desa Cibodas terletak di Kecamatan Lembang, Kabupaten Bandung Barat dan terletak 1.260 mdpl di atas ketinggian laut mempunyai luas wilayah 1.273,4 ha. Desa Cibodas memiliki batas-batas wilayah sebelah utara adalah Desa wangunharja, sebelah Selatan adalah Desa Ciburial, sebelah barat adalah Desa Langensari dan sebelah timur berbatasan dengan Desa Suntenjaya. Desa Cibodas merupakan daerah perbukitan dengan luas lahan terbesar merupakan lahan pertanian dan hutan konservasi TAHURA, kondisi tanahnya secara umum subur. Sebagian besar lahan di Desa Cibodas digunakan untuk wilayah pertanian. Selain pertanian Desa Cibodas juga dikembangkan peternakan sapi perah. Wilayah ini merupakan salah satu pemasok utama susu murni di Kecamatan Lembang.

Keberadaan perternakan sapi perah ini dimanfaatkan oleh beberapa warga mengembangkan biogas di Desa Cibodas. Dengan memanfaatkan kotoran sapi yang melimpah untuk menjadi gas yang bisa digunakan untuk keperluan sehari-hari dan air hangat untuk keperluan sapi perah. Strategi terbaik adalah untuk mengelola dan memanfaatkan kotoran sapi sebagai sumber "biomassa" daripada membuang mereka pergi sebagai "sampah", sehingga energi dan ekonomi manfaat, serta manfaat lingkungan, dapat direalisasikan. Oleh karena itu, anaerobic digestion dari kotoran sapi akan menjadi cara yang lebih baik dari pemanfaatan limbah (Wu dan Zhou, 2011). Pengolahan sampan untuk pembangkit energi, dan lebih lanjut sebagai pupuk organik diperkaya untuk pertanian organik dan untuk menyediakan kredit karbon (Emad, Flynn, dan Checkel, 2007). Hidrolisis enzimatik limbah makanan juga menghasilkan metana dengan menggunakan bio-reaktor (Bulan dan Song, 2011). Pemanfaaatan gas ini juga berdampak signifikan pada pengurangan pengeluaran rumah tangga di Desa Cibodas, rata-rata pemilik biogas tidak lagi bergantung pada LPG dan kayu bakar.

Prinsip utama biogas adalah mengkonversikan limbah kotoran menjadi energi terbaharukan, sehingga dapat mengurangi pemakaian energi tidak terbaharukan [1]. Selain itu, inovasi penggunaan sumber energi dari biogas juga dimaksudkan untuk menurunkan kontribusi penggunaan bahan bakar gas yang berdampak pada perubahan iklim (FCCC) untuk menstabilkan konsentrasi atmosfer gas rumah kaca di bawah tingkat berbahaya [2]. Pembuatan biogas di Desa Cibodas sudah dimulai sejak tahun 2004, namun pemakaian secara masal baru mulai pada tahun 2011 dan 2012. Inovasi menghasilkan banyak insentif bagi masyarakat [3]. Insentif yang diterima berupa pengurangan pemakaian listrik dan gas untuk rumah tangga. Masyarakat Desa Cibodas pada memanfaatkan gas olahan biogas untuk menggantikan penggunaan gas LPG, dan kelebihan gas digunakan untuk petromax namun masih belum optimal.

Pada penggunaan biogas pada umumnya, pemanfaatan terjadi hanya pada gas metana yang dihasilkan dari proses pertama sedangkan pengolahan lanjutan sering diabaikan, biosulry sebagai produk samping kegunaannya sering diabaikan pengguna biogas. Pada umumnya kegunaan biosulry sama dengan pupuk kandang lansung, namun manfaatnya agak sedikit berbeda. Biosulry adalah pupuk kandang yang telah hilang gas metananya, sehingga menjadi lebih ringan dari pupuk kandang lansung. Biosulry cair bisa lansung digunakan sebagai pupuk semprot dengan penambahan air dan penyaringan. Biosulry padat tidak lagi mengandung urin berlebih yang bisa membunuh mikroba yang menyebabkan kerusakan pada tanaman. 
Bahan baku yang digunakan untuk biogas di Desa Cibodas adalah kotoran sapi perah. Kotoran sapi ditambah air dalam rasio tertentu (campuran ini dikenal sebagai bubur) untuk mengoptimalkan produksi biogas dan pencernaan bakteri yang berlangsung dalam digester anaerobik. Bakteri selanjutnya menguraikan gas metan pada kotoran ternak, sehingga tekanan gas pada biodigester meningkat, sehingga didalam biodigerter terdapat tiga jenis produk olahan yaitu produk utama berupa gas dan produk sampingan berupa biosulry padatan dan cairan, seperti pada poin 2 pada gambar 1.

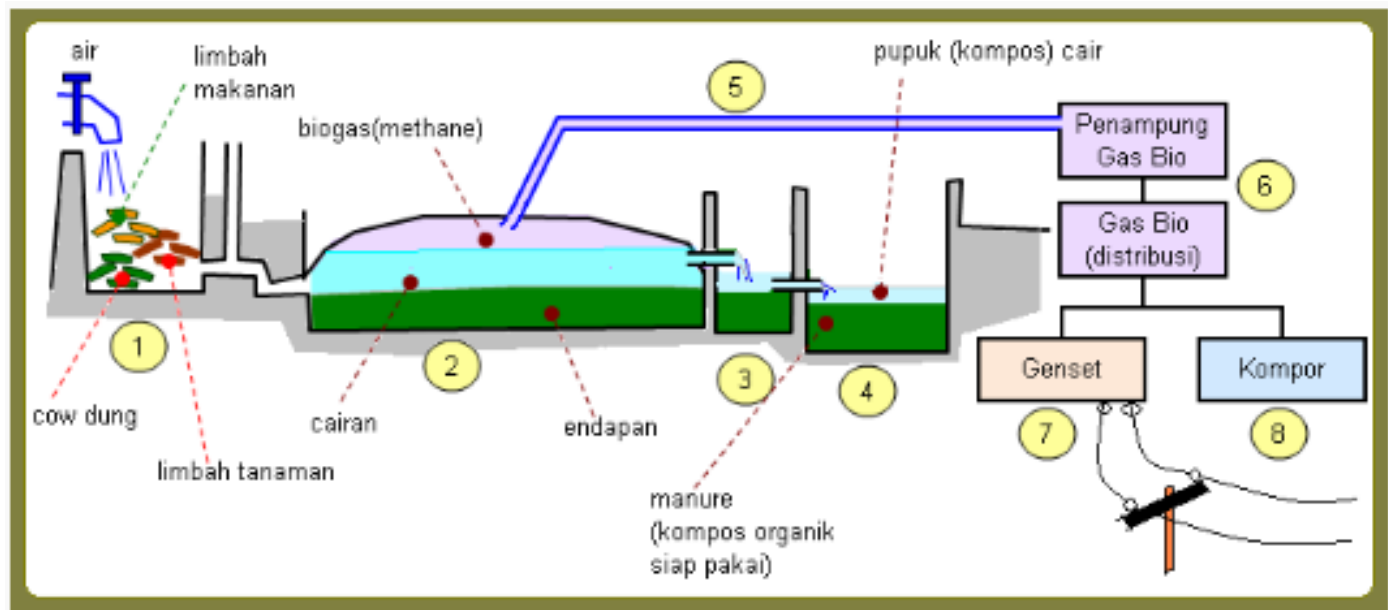

Gambar 1. Proses Pengolahan Biogas

Sumber: http://majalahenergi.com/

Di Desa Cibodas, Bandung Barat, terjadi suatu fenomena pemafaatan produk samping berlapis. Produk samping disini adalah berupa kotoran sapi, dapat dimodelkan dalam persamaan sederhana

Pengolahan berlapis di Desa Cibodas, pertama terjadi pada pengolahan kotoran sapi menjadi biogas dengan produk samping berupa biosulry, kedua terjadi pada pengolahan produk samping biosulry menjadi pupuk kascing (bekas cacing). Biosulry keluar berupa padatan dan cairan. Biosulry keluar akibat adanya tekanan yang dihasilkan dari pengolahan bahan baku kotoran sapi oleh bakteri didalam bioreactor. Biosulry bisa dimanfaatkan lansung sebagai pupuk yang kualitasnya lebih baik dari pupuk kandang dikarenakan pemisahan gas metan oleh bakteri. Selain itu biosulry padat juga masih bisa diolah menjadi kascing, dengan menggunakan cacing khusus yang menjadikan biosulry media yang lebih bagus untuk tanaman. Sedangkan biosulry cair bisa digunakan lansung sebagai pupuk lansung dengan penambahan air sesuai kadarnya. Pengolahan berlapis ini ini tentu akan menghasilkan keuntungan berlapis juga. Penelitian ini dilakukan untuk memperlihatkan penggunaan dan keuntungan pengolahan berlapis di Desa Cibodas.

\section{Metode}

Survey yang dilakukan pada penelitian ini adalah survey primer dengan menggunakan kuisioner terbatas [4] [5] [6]. Responden pada penelitian adalah semua peternak sapi perah yang menggunakan biogas di Desa Cibodas. Survey dilaksanakan dalam waktu tiga hari dan mendapatkan 79 responden yang menggunakan biogas dan memiliki limbah buangan biogas. Responden yang didapatkan terdiri dari $63 \%$ laki-laki dan $37 \%$ perempuan, pada dasarnya responden dilihat perkeluarga, pembagian responden berdasarkan jenis kelamin dilakukan untuk melihat persepsi responden terhadap hasil limbah biogas. 79 responden mewakili 79 keluarga yang memakai biogas.

\section{Hasil dan analisis / pembahasan}

Semua gambar harus diletakkan di tengah dan diberi judul gambar seperti pada gambar 1 Dari survei yang dilakukan didapatkan data sebagai berikut

\begin{tabular}{|l|l|l|}
\hline No. & $\begin{array}{l}\text { Pengolahan limbah biodigester } \\
\text { (biosulry) menjadi kompos }\end{array}$ & Persentase \\
\hline 1. & Diolah menjadi kompos & $57 \%$ \\
\hline 2. & Tidak diolah menjadi kompos & $43 \%$ \\
\hline
\end{tabular}

Tabel 1. Persentase pengolahan limbah biodigester menjadi kompos 
Jumlah kotoran yang dimasukan ke biodigester oleh 79 responden sebanyak 360 ember per hari dengan rata-rata 6 ember peresponden. Data ini menunjukan ketersediaan limbah biogas sebanyak 360 ember perharinya, jika 1 ember adalah $15 \mathrm{~kg}$ maka perharinya limbah biogas dari 79 responden adalah $5400 \mathrm{~kg}$ perhari. Hal ini berimplikasi pada ketersediaan pupuk perhari sebanyak $5400 \mathrm{~kg}$ perhari untuk limbah solid saja, sedangkan limbah cair juga tersedia dengan jumlah yang sama. Sehingga total pupuk yang dihasilkan, liquid dan solid, adalah $10800 \mathrm{~kg}$ perhari, jika pupuk dihargai Rp. 500,- perkilonya maka total penghasilan yang akan didapatkan adalah 5,4 juta rupiah untuk 79 responden atau 68 ribu peresponden.

\begin{tabular}{|c|c|c|}
\hline No & Penggunaan pupuk Urea/NPK untuk pertanian & Jumlah \\
\hline 1 & sebelum penggunaan biosulry & $6393 \mathrm{~kg}$ \\
\hline \multirow[t]{3}{*}{2} & sesudah memakai biosulry & $4208 \mathrm{~kg}$ \\
\hline & Selisih & $2185 \mathrm{~kg}$ \\
\hline & konversi harga (1kg:Rp.2000,-) & $4.370 .000,00$ \\
\hline
\end{tabular}

Tabel 2. Penggunaan pupuk Urea/NPK untuk pertanian sebelum dan sesudah pemakaian biosulry

Dari survey yang sama didapatkan hasil data yang berbeda tentang jumlah biosulry yang dihasilkan. Data yang didapatkan menunjukan rata-rata biosulry yang dighasilkan adalah 3 ember perharinya, perbedaan data hitungan dn data yang didapat ini menimbulkan kerancuan. Namun jika berpedoman pada rata-rata biosulry yang dihasilkan perhari yaitu 3 ember, untuk setiap ember beratnya adalah 15kg, yang berarti ada $45 \mathrm{~kg}$ biosulry/responden perharinya. Jika dikonfersikan ke capital dengan perhitungan yang sama yaitu pupuk dihargai Rp. 500,- perkilonya, maka total penghasilan yang didapatkan responden adalah Rp. 2.2500 ,- perharinya atau Rp. $675.000,-$ perbulannya.

Dari hasil survey diketahui juga bahwa penggunaan total gas LPG perbulan sebelum responden menggunakan biogas adalah 216, sedangkan setelah penggunaan biogas penggunaan Ipg total berkurang menjadi $71 \mathrm{lpg}$ perbulan. Penghematan penggunaan gas LPG terjadi sekitar $70 \%$ dari awal penggunaan. Jika harga satu tabung gas LPG adalah Rp. 25.000,- penghematan yang dilakukan perbulannya adalah sekitar Rp.3.625.000,- perbulan. Jika dibandingkan dengan penghematan pemakaian biosulry dengan pengurangan jumlah pemakaian pupuk urea/NPK saja maka didapatkan penghematan Rp. 4.370.000,perpemakaian pupuk. Hal ini belum disertai data percepatan pertumbuhan tanaman dan ditambah dengan hasil biosulry yang bisa dijual dipasar.

\begin{tabular}{|l|l|l|}
\hline No & Apakah semua kotoran sapi dimasukan kedalam biodigester & Persentase \\
\hline 1. & Ya, semua kotoran sapi dimasukan kedalam biodigester & $61 \%$ \\
\hline 2. & Tidak, tidak semua kotoran sapi dimasukan dalam biodigester & $39 \%$ \\
\hline & Jika tidak kemana kotoran sapi tersebut dibuang? & \\
\hline $2 a$ & Dibuang ke selokan menuju sungai & $11 \%$ \\
\hline $2 b$ & Dibuang ke lahan kosong & $14 \%$ \\
\hline $2 c$ & Dalihkan kelahan pertanian & $59 \%$ \\
\hline $2 d$ & Lainnya & $16 \%$ \\
\hline
\end{tabular}

Tabel 3. Persentase pengolahan kotoran dalam biogás

Sebagian besar responden memakai semua kotoran sapinya untuk dimasukan kedalam biodigester. Memasukan banyak kotoran sapi sebagai bahan bakar biogas bukan merupakan hal yang bisa dianggap baik. Perlu dilihat kuantitas optimal yang sanggup ditampung biodigester agar dapat menghasilkan biogas dengan maksimal. Begitu juga dengan kualitas dar biosulry yang dihasilkan jika proses penguraian gas metan tidak optimal, kualitas biosulry akan menurun. 


\begin{tabular}{|l|l|l|l|l|}
\hline \multirow{2}{*}{ No. } & Penghasilan bulanan & \multirow{2}{*}{ Persentase } & \multicolumn{2}{|l|}{ Pengolahan Biosulry } \\
\cline { 4 - 5 } & & & Ya & Tidak \\
\hline 1. & Kurang dari Rp 500.000,- & $2 \%$ & $0 \%$ & $100 \%$ \\
\hline 2. & Rp. 500.000,- s/d Rp. 1.000.000,- & $12 \%$ & $67 \%$ & $33 \%$ \\
\hline 3. & Rp. 1.000.000,- s/d Rp. 2.500.000,- & $56 \%$ & $57 \%$ & $43 \%$ \\
\hline 4. & Rp. 2.500.000,- s/d Rp. 5.000.000,- & $25 \%$ & $58 \%$ & $42 \%$ \\
\hline 5. & Diatas Rp. 5.000.000,- & $5 \%$ & $50 \%$ & $50 \%$ \\
\hline \multicolumn{2}{|l|}{ Rata-rata perpenghasilan } & $46 \%$ & $54 \%$ \\
\hline
\end{tabular}

Tabel 4. Pengolahan biodigester dengan penghasilan bulanan penduduk

Dari tabel diatas dapat dilihat persentase pengolahan biosulry jika dibandingkan dengan penghasilan bulanan. Dengan spss didapatkan korelasi negatif dengan nilai -0,0006 yang berarti pengolahan biosulry tidak berkorelasi dengan tingkatan penghasilan bulanan peternak sapi di Desa Cibodas. Namun dilihat dari data lainnya, perlu diadakan pendataan ulang terkait penambahan penghasilan bulanan akibat pengolahan biosulry.

Pekerjaan utama responden adalah peternak sapi perah, 54\% peternak sapi dan 39\% petani dan peternak.

\begin{tabular}{|l|l|l|}
\hline No & Pekerjaan & Persentase \\
\hline 1. & Petani & $3 \%$ \\
\hline 2. & Peternak Sapi perah & $54 \%$ \\
\hline 3. & Petani dan peternak & $39 \%$ \\
\hline 4. & Lainnya & $4 \%$ \\
\hline
\end{tabular}

Tabel 5. Pekerjaan utama responden

Dikarenakan responden yang diharapkan adalah pengguna biogas maka data selanjutnya yang disajikan adalah pemanfaatan kotoran sapi untuk biogas.

\begin{tabular}{|l|l|l|}
\hline No. & $\begin{array}{l}\text { Apakah kotoran sapi perah } \\
\text { dimanfaatkan untuk keperluan } \\
\text { digester biogas? }\end{array}$ & Persentase \\
\hline 1. & Ya & $83 \%$ \\
\hline 2. & Tidak & $17 \%$ \\
\hline
\end{tabular}

Tabel 6. Persentase pemanfaatan kotoran sapi untuk biogás

Dari data diatas masih ada sebagian responden yang tidak memanfaatkan kotoran sapi untuk keperluan biodigester atau pembuatan biogas. Hal ini juga dikarenakan kerusakan-kerusakan yang terjadi pada biodigester yang dikarenakan banyak hal, dan tidak menjadi fokus penelitian ini. sebagian besar, $83 \%$ responden, masih dapat mempergunakan biogas dan masih memanfaatkan kotoran sapi perah mereka untuk keperluan biodigester. Data selanjutnya memperlihatkan volume biodigester yang dipakai oleh responden. Rata-rata responden memakai umuran $4 \mathrm{~m} 3$, yang merupakan program PT. BIRU. 


\begin{tabular}{|l|l|r|}
\hline No. & Volume digester & Persentase \\
\hline 1 & $6 \mathrm{~m} 3$ & $39,0 \%$ \\
\hline 2 & $8 \mathrm{~m} 3$ & $5,2 \%$ \\
\hline 3 & $12 \mathrm{~m} 3$ & $1,3 \%$ \\
\hline 4 & $4 \mathrm{~m} 3$ & $53,2 \%$ \\
\hline 5 & Lainnya & $1,3 \%$ \\
\hline
\end{tabular}

Tabel 7. volume digester yang dipakai

Ada beberapa responden yang menambah kapasitas biodigester untuk mendapatkan biogas yang lebih banyak. Kapasitas biodigester juga akan mempengaruhi jumlah kotoran masuk dan biosulry yang dikeluarkan nantinya. Semakin besar volumenya semakin banyak kotoran yang dibutuhkan dan semakin banyak juga biosulry yang dihasilkan.

\section{Kesimpulan}

Dari data-data yang disajikan diatas dapat ditarik kesimpulan bahwa pemanfaatan berlapis memberikan dampak positif bagi penambahan penghasilan dan pengurangan pencemaran lingkungan. Selain itu hasil wawancara dengan responden juga menunjukan adanya perbedaan periode panen sebelum dan sesudah pemakaian biosulry pada lahan pertanian responden, pemakaian biosulry berdampak positif pada penambahan kualitas dan kuantitas tanaman. Namun pengelolaan berlapis di Desa Cibodas nampaknya kurang optimal, hal ini diperlihatkan dari penembahan penghasilan yang masih sedikit dan antusiasme pengolahan yang masih kurang, untuk itu perlu dijalankan suatu program penyuluhan yang mengkampanyekan pengolahan berlapis pada penduduk. Program penyuluhan bertujuan untuk (1) Membangkitkan kesadaran masyarakat, mengenai pentingnya mengolah produk sisa dengan benar dan mengajak masyarakat engguna biogas untuk melakukan pemanfaatan produk sisa biogas; (2) Merencanakan dan merancang skema pengolahan produk sisa biogas benar dan optimal; dan (3) Membuka pasar bagi olahan produk sisa biogas.

\section{Penghargaan}

Terima kasih kepada tim RDI yang telah menyediakan sumberdaya untuk melakukan pengambilan data.

\section{Daftar Pustaka}

[1] G. Berndes, "The contribution of biomass in the future global energy supply: a review of 17 studies. Biomass and Bioenergy 25 (2003)," Elsavier, vol. Biomass and Bioenergy 25, p. 1-28, 2002.

[2] G. T. Tucho, ". Bio-Wastes as an Alternative Household Cooking Energy Source in Ethiopia," Elsevier, no. Energies, 2015.

[3] C. Montgomery, Happy City, Canada: Penguin Book, 2013.

[4] J. Creswell, Research Design: Qualitative, Quantitative, and Mixed Methods Approaches, California: Sage Publications, Inc, 2008.

[5] J. Creswell, Educational Research: Planning, Conducting, and Evaluating Quantitative and Qualitative Research., New Jersey: Prentice Hall, 2004.

[6] M. Singarimbun dan S. Effendi, Metode Penelitian Survai, Jakarta: Penerbit Pustaka LP3ES, 2006.

[7] D. Deublein dan A. Steinhauser, "Biogas from Waste and Renewable Resources: An Introduction," John Wiley \& Sons: Hoboken, NJ, USA,, no. Biogas and Energy, 2011.

[8] B. Kebede, A. Bekele dan E. Kedir, "Can the urban poor afford modern energy? The case of Ethiopia," Elsavier, vol. 30, no. Energy Policy, p. 1029-1045, 2002. 
[9] F. Rosillo-Calle, "The Biomass Assessment Handbook: Bioenergy for a Sustainable Environment;," Earthscan: London, UK, 2007.

[10] J. Jetter dan P. Kariher, "Solid-fuel household cook stoves: Characterization of performance and emissions.," Elsevier, vol. 33, no. Biomass Bioenergy, pp. 294-305, 2009.

[11] U. N. Ngoc, "Sustainable solutions for solid waste management in Southeast Asian countries," Elsevier, vol. 29, no. Waste Management, p. 1982-1995, 2009. 